\title{
Five-Year Analysis of Mandible Fracture and its Associated Factors
}

\author{
Chai Siew Cheng ${ }^{1}$, Yew Ching Ching ${ }^{2}$, Wan Azman Wan Sulaiman ${ }^{1}$, \\ Shaifulizan Abdul Rahman ${ }^{2}$ \\ ${ }^{1}$ Reconstructive Sciences Unit, School of Medical Sciences, Universiti Sains Malaysia, Kubang \\ Kerian, Kelantan 16150, Malaysia \\ ${ }^{2}$ Oral and Maxillofacial Surgery Unit, School of Dental Science, Universiti Sains Malaysia, Kubang Kerian, \\ Kelantan 16150, Malaysia
}

\begin{abstract}
This retrospective study evaluated the mandibular fracture in patients who presented our center between January Year 2011 to December Year 2015. A total of 222 patients with 368 mandibular fractures were analysed. The age of patients ranged from 3 to 76 years old (mean age 23.3) with peak incidence occurring in the 10 to 19 years age group. The Male to female ratio was 5.5:1. The most common cause of injury was motor vehicle accident (MVA) (91\%), followed by fall (2.7\%) and intentional injury (2.7\%). The most common site of fracture was the parasymphysis (29.9\%), followed by condyle (21.7\%) and angle (15.2\%). A total of 75 patients (33.8\%) sustained other maxillofacial fractures and 143 patients (64.4\%) sustained nonmaxillofacial injuries. Motorcycle related accidents, especially without a helmet, demonstrated close relation to the high incidence of parasymphyseal fracture; causing more severe maxillofacial injury, head and neck injuries and extremities injury. In term of treatment for mandibular fractures, $69.4 \%$ of patients underwent open reduction and internal fixation, $15.8 \%$ of patients required intermaxillary fixation and $11.7 \%$ of patients had conservative treatment with soft diet. The finding of this study indicated that the pattern of mandibular fracture is related to the causative factor; therefore additional preventive measures should be accomplished.
\end{abstract}

Keywords- Facial fracture, mandibular fracture, maxillofacial trauma

\section{Introduction}

Facial injury can had a deliberating effect on victims physically, functionally and physiologically. Mandibular fracture is one of the most common fractures in maxillofacial trauma. The incidences, based on several studies, ranged from 37\% to 70\% [1-6]. Data compilation regarding maxillofacial trauma is valuable in terms of treatment planning and future development of preventive programs. By reviewing the published literatures, the most common causes for maxillofacial trauma include assaults, motor vehicle accidents (MVA) and fall depending on the geographical area, socio-economics of the study population and mobility of the population.

This present study was a retrospective survey in Hospital University Sains Malaysia (HUSM), which is the one out of two main tertiary referral centres in Kelantan. The aims of this study include: (1) identifying the pattern of mandibular fracture and related causative factors, (2) determining the risk age group and gender involved in facial trauma, (3) recognising the associated maxillofacial trauma and non-maxillofacial trauma in relation to the cause and (4) establishing treatment options for mandibular fracture.

\section{Method/ Material}

This is a retrospective study concerning the patients who were treated for mandibular fracture from January Year 2011 to December Year 2015 in Hospital Universiti Sains Malaysia (HUSM). HUSM is located in Kelantan, a state of the East Coast of Peninsular Malaysia with a total estimated population of 1.71 million. A total of 222 consented patients were included in the study. Medical records of all the patients were reviewed. Data containing demographic details, mechanism of injury, site of mandibular fracture, associations with other maxillofacial fractures, nonmaxillofacial injuries, as well as, management of mandibular facture were collected using designed proforma. The data were analysed using SPSS version 21.0. Descriptive statistic results were presented in the form of frequencies, percentage and mean.

\subsection{Demorgraphic Details}

\section{Result}

From the total of 222 patients, there were 188 male patients (84.7\%) and 34 female patients (15.3\%). The ratio of males to females was 5.5:1. The mean age of patients was 23.3 years old, ranging from 3-year olds 
to 76-year olds. The most affected age group was between the ages of 10 to 19 with 101 patients $(45.5 \%)$. This group was followed by the patients in their 20 s, with 76 patients (34.2\%). Males were outnumbered by females in all age groups except the 0 to 9 years age group and 60 to 69 years age group (Fig.1).

\subsection{Aetiology of Mandibular Fracture}

The most common cause of fracture was motor vehicle accident (MVA), involving 202 patients (91\%, 170 males and 32 females). Other causes were falls (6 patients, 2.7\%), intentional injuries (6 patients, 2.7\%), industrial injuries (3 patients, 1.4\%) and sport-related fracture ( 2 patients, $0.9 \%)$. In 3 additional cases, 2 patients with epilepsy were presented with fracture post fitting episode, and 1 patient sustained pathological fracture secondary to trivial injury. In comparison with age groups, MVA was still the main etiologic factor of fractures in all age groups (Table 1).

In the group of 202 patients involved in MVA, 168 patients (83.2\%) were motorcyclists. One hundred and eighteen patients were not wearing helmets and only 50 patients were documented to wear helmets during the accidents. Twenty-seven patients (13.3\%) were either four-wheel vehicle drivers or passengers. The others 7 patients were involved in motor vehicle-pedestrian or other motor vehicle-related injuries. In motorcycle-related injuries, the peak incidence was in the 10 to 19 years age range; whereas in four-wheel vehicle accidents, the peak incidence was at 20 to 29 years age group.

\subsection{Frequencies and Anatomical Distribution Of Mandibular Fracture}

A total of 368 mandibular fracture lines were identified in 222 patients, averaging 1.7 fractures per patient. The numbers of patients with one fracture line were 97 patients $(43.7 \%)$, two fracture lines were 105 patients $(47.3 \%)$ and three fracture lines were 20 patients. Two hundred and one patients (90.5\%) sustained closed mandibular fractures and 21 patients $(9.5 \%)$ sustained open mandibular fractures. There were 156 (45.1\%) left-sided fractures, 156 (42.4\%) right-sided fractures and $53(9.5 \%)$ symphyseal fractures.

The most common fracture site was parasymphysis (110 fractures, $29.9 \%)$, followed by $80(21.7 \%)$ condylar fractures and $56(15.2 \%)$ mandibular angle fractures. Anatomical distributions of other fracture sites which included symphysis, coronoid, body and ramus were shown in Fig. 2.

The causes of mandibular fractures and their relation with the anatomical distribution of the fracture were shown in Table 2. In motor vehicle accidents, the most common fracture site was parasymphysis (101 fractures), regardless of whether patients were involved in motorcycle-related injury or four-wheel vehiclerelated injury. Condylar fracture (73 fractures) was the second most common site of fracture in MVA.

\subsection{Other Maxillofacial Fracture Associated With Mandibular Fracture}

In this study, 147 out of 222 patients $(66.2 \%)$ sustained mandibular fractures only. Seventy-five patients (33.8\%) sustained mandibular fracture and other facial fractures. There was a total of 118 other facial fractures identified in association with mandibular fracture. The most common was zygomatic fractures, followed by maxillary fractures and orbital fractures. Fig. 3 displayed the anatomical distribution of other facial fractures associated with the mandibular fracture.

\subsection{Nonmaxillofacial Injury Associated With Mandibular Fracture}

A total of 143 out of 222 patients $(64.4 \%)$ in this study were presented with nonmaxillofacial injury. This associated injury was divided into 4 main categories: head and cervical injury, thoracic injury, abdominal injury and extremities injury. Motorcycle-related accidents without a helmet and four-wheel vehicle accidents without seat restraints were shown to have high prevalence of polytrauma where patients sustained more than 2 categories of injury (Table 3). The most common associated injury was head and cervical injury $(75.5 \%)$, followed by extremities injury (46.9\%) and thoracic injury (22.3\%) (Table 4).

\subsection{Treatment of Mandibular Fracture}

A total of 26 patients $(11.7 \%)$ were conservatively treated due to favourable fracture and intact occlusion. Of these 26 patients, 19 patients had single mandibular fracture, 5 had two fractures and only 2 had three fractures. Sixteen out of 26 of these patients sustained injuries associated with condylar fracture.

For unfavourable mandibular fracture, 154 patients $(69.4 \%)$ were surgically treated with open reduction and internal fixation with plates. Of these 154 patients, 79 patients had 2 fractures, 62 had a single fracture and 13 had 3 fractures.

Another 35 patients (15.8\%) were treated with intermaxillary fixation with upper and lower arch bars for 4-6 weeks. In this group of patients, 14 had single fractures, 17 had 2 fractures and 4 had 3 fractures. Seven patients $(3.2 \%)$ defaulted treatment after diagnosis. 


\section{Figures And Tables}

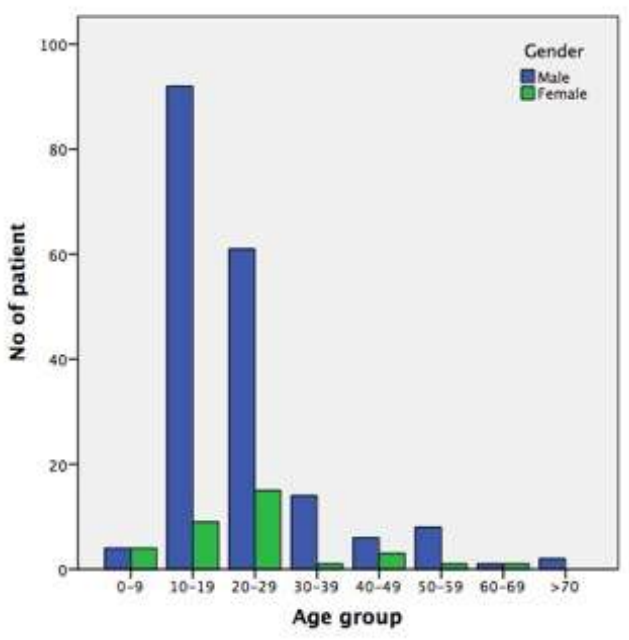

Fig. 1: Gender and age group distribution

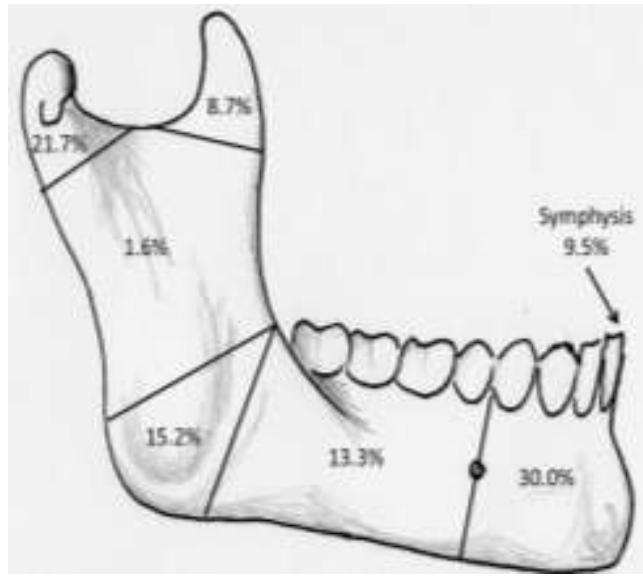

Fig. 2: Anatomical distribution of mandibular

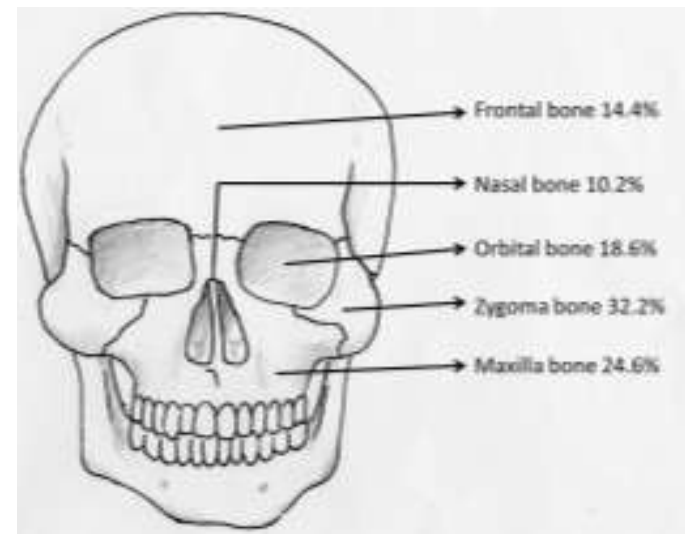

Fig 3: Anatomical distribution of other maxillofacial fracture 
Table 1: Causes in relation to age group

\begin{tabular}{|c|c|c|c|c|c|c|c|c|c|}
\hline \multirow[t]{2}{*}{ Cause } & \multicolumn{8}{|c|}{ Age Group } & \multirow[b]{2}{*}{ Total } \\
\hline & $0-9$ & $10-19$ & $20-29$ & $30-39$ & $40-49$ & $50-59$ & $60-69$ & $>70$ & \\
\hline MVA & 7 & 93 & 71 & 14 & 6 & 7 & 2 & 2 & 202 \\
\hline Fall & 1 & 3 & 1 & 0 & 1 & 0 & 0 & 0 & 6 \\
\hline Sports & 0 & 1 & 1 & 0 & 0 & 0 & 0 & 0 & 2 \\
\hline Indurtrial injury & 0 & 0 & 1 & 0 & 1 & 1 & 0 & 0 & 3 \\
\hline Intentional injury & 0 & 3 & 1 & 1 & 1 & 0 & 0 & 0 & 6 \\
\hline Others & 0 & 1 & 1 & 0 & 0 & 1 & 0 & 0 & 3 \\
\hline Total & 8 & 101 & 76 & 15 & 9 & 9 & 2 & 2 & 222 \\
\hline
\end{tabular}

Table 2: Distribution cause of fracture and anatomical distribution of fracture

\begin{tabular}{|c|c|c|c|c|c|c|c|c|c|c|}
\hline \multirow[t]{2}{*}{ Cause } & & \multicolumn{9}{|c|}{ Site of fracture } \\
\hline & & Symphysis & $\begin{array}{l}\text { Post. } \\
\text { Body }\end{array}$ & Ant. Body & $\begin{array}{l}\text { Parasymph } \\
\text { ysis }\end{array}$ & Condyle & Coronoid & Ramus & Angle & \\
\hline \multirow[t]{6}{*}{ MVA } & Motocyclist with helmet & 2 & 3 & 8 & 26 & 16 & 8 & 3 & 17 & 83 \\
\hline & Motocyclist without helmet & 23 & 8 & 21 & 58 & 42 & 17 & 0 & 22 & 191 \\
\hline & $\begin{array}{l}\text { Four wheel-vehicle with } \\
\text { seatbelt }\end{array}$ & 3 & 0 & 3 & 8 & 7 & 4 & 0 & 2 & 27 \\
\hline & $\begin{array}{l}\text { Four wheel-vehicle without } \\
\text { seatbelt }\end{array}$ & 2 & 0 & 0 & 7 & 5 & 1 & 2 & 3 & 20 \\
\hline & Pedestrian & 0 & 1 & 1 & 1 & 0 & 0 & 0 & 2 & 5 \\
\hline & Unknown & 2 & 0 & 0 & 1 & 3 & 0 & 0 & 1 & 7 \\
\hline \multicolumn{2}{|l|}{ Fall } & 1 & 1 & 0 & 3 & 3 & 0 & 0 & 3 & 11 \\
\hline \multicolumn{2}{|l|}{ Sports } & 0 & 0 & 0 & 0 & 0 & 2 & 0 & 1 & 3 \\
\hline \multicolumn{2}{|c|}{ Industrial injury } & 0 & 0 & 0 & 2 & 0 & 0 & 1 & 2 & 5 \\
\hline \multicolumn{2}{|c|}{ Intentional injury } & 1 & 0 & 1 & 4 & 1 & 0 & 0 & 3 & 10 \\
\hline \multirow{2}{*}{\multicolumn{2}{|c|}{ Others }} & 1 & 1 & 1 & 0 & 3 & 0 & 0 & 0 & 6 \\
\hline & & 35 & 14 & 35 & 110 & 80 & 32 & 6 & 56 & 368 \\
\hline
\end{tabular}

Table 3: Number of associated nonmaxillofacial injury in relation to cause of injury

\begin{tabular}{|c|c|c|c|c|c|c|c|}
\hline \multirow[t]{2}{*}{ Cause } & & \multicolumn{5}{|c|}{ Number of associated injury } & \multirow[t]{2}{*}{ Total } \\
\hline & & 0 & 1 & 2 & 3 & 4 & \\
\hline \multirow[t]{6}{*}{ MVA- } & Motocyclist with helmet & 29 & 18 & 2 & 1 & 0 & 50 \\
\hline & Motocyclist without helmet & 24 & 53 & 26 & 13 & 3 & 119 \\
\hline & Four wheel-vehicle with seatbelt & 7 & 6 & 2 & 0 & 0 & 15 \\
\hline & Four wheel-vehicle without seatbelt & 2 & 5 & 1 & 4 & 0 & 12 \\
\hline & Pedestrian & 2 & 2 & 0 & 0 & 0 & 4 \\
\hline & Unknown & 0 & 2 & 0 & 0 & 0 & 2 \\
\hline \multicolumn{2}{|l|}{ Fall } & 4 & 2 & 0 & 0 & 0 & 6 \\
\hline \multicolumn{2}{|c|}{ Sports injury } & 2 & 0 & 0 & 0 & 0 & 2 \\
\hline \multicolumn{2}{|c|}{ Industrial injury } & 2 & 1 & 0 & 0 & 0 & 3 \\
\hline \multicolumn{2}{|c|}{ Intentional injury } & 5 & 1 & 0 & 0 & 0 & 6 \\
\hline \multicolumn{2}{|l|}{ Others } & 2 & 1 & 0 & 0 & 0 & 3 \\
\hline & & 79 & 91 & 31 & 18 & 3 & 222 \\
\hline
\end{tabular}

Table 4: Distribution of causes of injury and categories of nonmaxillofacial injury

\begin{tabular}{|c|c|c|c|c|c|}
\hline & & \multicolumn{4}{|c|}{ Category of associated injury } \\
\hline & & Head and cervical injury & $\begin{array}{l}\text { Thoracic } \\
\text { imiury }\end{array}$ & $\begin{array}{l}\text { Abdominal } \\
\text { injury }\end{array}$ & $\begin{array}{l}\text { Extremity } \\
\text { injury }\end{array}$ \\
\hline \multirow[t]{6}{*}{ MVA - } & Motocyclist with helmet & 8 & 5 & 1 & 11 \\
\hline & Motocyclist without helmet & 79 & 21 & 8 & 47 \\
\hline & Four wheel-vehicle with seatbelt & 6 & 1 & 0 & 3 \\
\hline & Four wheel-vehicle without seatbelt & 8 & 5 & 3 & 3 \\
\hline & Pedestrian & 2 & 0 & 0 & 1 \\
\hline & Unknown & 2 & 0 & 0 & 0 \\
\hline \multicolumn{2}{|r|}{ Hollown } & 1 & 0 & 0 & 1 \\
\hline \multicolumn{2}{|c|}{ Sports injury } & 0 & 0 & 0 & 0 \\
\hline \multicolumn{2}{|c|}{ Industrial injury } & 1 & 0 & 0 & 0 \\
\hline \multicolumn{2}{|c|}{ Intentional injury } & 1 & 0 & 0 & 0 \\
\hline \multicolumn{2}{|c|}{ Others } & 0 & 0 & 0 & 1 \\
\hline & Total of patient' total of patient with as sociated injury & $108 / 143$ & $32 / 143$ & $12 / 143$ & $67 / 143$ \\
\hline MVA: 1 & otor vehicle accident & & & & \\
\hline
\end{tabular}


Table 5 Summary of literatures of commonest site of fracture in relation to the cause of injury

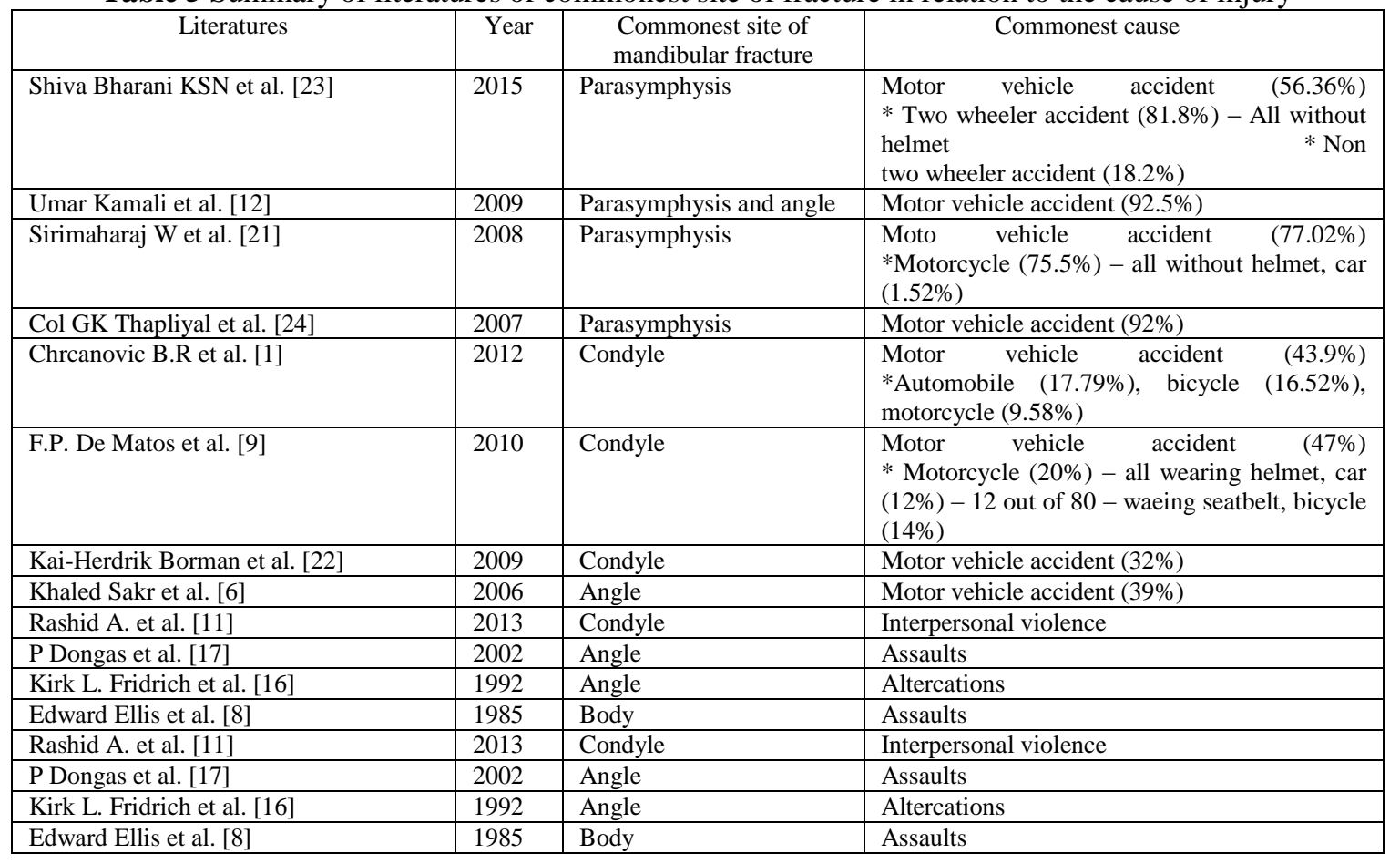

\section{Discussion}

Geographic area, socioeconomic status, regional government, culture and density of studied population are the contributing factors that influence the epidemiologic surveys of mandibular fracture [2, 7-9]. Enforcement and revision of new law regulations (for example seatbelt and helmet laws) can lead to the change of epidemiology of mandibular fracture [8].

Gender distribution of recent studies was similar, with male preponderance; ratio male to female can range from 4:1 to $6: 1[1,9-11]$. However, the most affected age group in our study was the 10 to 19 years age group. This finding was consistent with our previous study [12], but in contrast to others studies that had the peak age group of 20 to 29 years and above [1, 8-11, 13-17]. Male patients were generally more active in outdoor and social activities. The involvement of younger age group patients (10-19 years old) in our study is a worrisome finding since they are the future resources of our country. Their involvement is multifactorial in nature but can be generally associated with tendency of excessive risk taken by young people [18], permitted age for motorcycle riding at 16 years (by Road Transport Act 1987) and the possible insufficient integrated vigilance system involving the police and other governing authorities. In addition, there is a strong illegal motorcycle racing culture, known as the 'Mat Rempit' race in Malaysia which involves this age group of youth (as reported by Wong et al [19]) which directly increases the incidence of maxillofacial injury.

Motor vehicle accident (MVA) or road traffic accident $(91 \%)$ is still mainstay as the most common cause of mandibular fracture in our population; as in previous studies in Malaysia [4, 12]. This is also the most common cause of mandibular fracture in the studies of other countries [1, 6, 9, 20-24]. Intentional injury and falls were the second common causes of mandibular fracture in the present study; in contrast to other studies which had shown falls $[10,25]$ or intentional injury/violence $[8,11,16,17]$ as the most common. The difference in the main cause of injury is largely dependent on the cities where studied were conducted, as well as, the population. High incidence of MVA in our study may attributed to reckless driving, insufficient helmet and seatbelt usage and the availability of motorcycle for the young generation. Violence has been reported to have a strong correlation with alcohol consumption [17]. In our study, low incidence of intentional injury can be attributed to limited license allocation by the state government of Kelantan for selling liquor and Islamic culture, which prohibits alcohol consumption.

Motorcycle-related accidents were the main contributing factor to injury. Based on the Statistic Transport Malaysia Year 2013, Kelantan had a total of 475,606 registered motorcycles compared to 273,140 registered motorcars. This reflected on the lower economic status of the study population since the motorcycle is main mode of transport used. The motorcycle has lower purchase price, low maintenance fee and less cost in petrol usage. Among those involved in MVA, 70.4\% of motorcycle riders and $42.6 \%$ of four-wheel vehicle patients do not wear personal protective equipment even though Malaysia Helmet Law and Seatbelt Law were 
first implemented in 1973 and 1979, respectively. However, there is no legislation on child or baby-seat usage, in passenger vehicles.

A local study by S Kulanthayan et al. [26] reported that motorcyclists younger than 20 years of age with lower education levels, or riders with no licenses are found to have poor awareness of road safety. Although the current sample may not be representative of the Malaysian population, the results of this study appear to suggest that youngsters travelling by motorcycle are most vulnerable to motor vehicle accidents, which may lead to mandibular fractures. Hence, prevention campaigns specifically aimed at this age group of the population would be an appropriate method to improve overall motorcycle safety.

The anatomical distribution of mandibular fractures in relation to the cause of injury was variable in published literatures; as summarized in Table 5. In the present study, the most common mandibular fracture site was parasymphysis, which was consistent with a previous study in the same centre [12] and others studies in differents countries [21, 23, 24]. When MVA is the main cause of mandibular fracture considered, the commonest site of fracture was reported to be condyle [1, 9, 22] and angle [20], respectively. To identify the significant relation of the commonest site of mandibular fracture in relation to the cause of injury, more detailed data regarding MVA (including type of involved vehicle and the use of personal safety equipment) were highlighted in our study. We observed that patients of MVA involving 2-wheeled vehicles, without a helmet or with an open helmet, were susceptible to parasymphyseal fracture. This finding was further reported by Shiva et al. [23] and Sirimaharaj W et al. [21]. In the studies with high incidences of violence, the commonest site of fracture was mostly reported as the angle of the mandible $[11,16,17]$. In conclusion, the anatomical distribution of mandible fracture can be vary depending on the mechanism of injury, transmission of force along the mandible and demographic details of the patients. Detailed history of mechanism of injury (for example, type of vehicle in MVA, safety awareness of road safety, assault cases with or without weapons and clinical examinations) are crucial to help clinicians achieve an the accurate diagnosis.

Our study indicated that $33.8 \%$ of patients had at least one other maxillofacial fracture. This incidence was higher in compared to the incidence previously reported in Brazil (21.8\%) [1], Scotland (16\%) [14] and London (5\%) [11]. Zygomatic fracture was the most commonly associated fracture corresponding to other studies $[8,9,11]$ due to being anatomically more prone to injury. In the study of Rashid et al. [11], MVA caused more concurrent maxillofacial fracture even though violence was the commonest cause of mandibular fractures. The result of this study also indicated that MVA lead to more severe maxillofacial injury, especially in motorcycle-related accidents. A total of 143 out of 222 patients $(64 \%)$ in our study had other nonmaxillofacial injury. MVA further caused higher incidence of injury to other parts of the body compared to assault injury; as reported by Ellis et al. [8]. Motorcycle-related accidents without helmet led to more severe injuries; especially head and neck injuries and extremities injury as previous mention. Based on this study, MVA resulted in more severe injuries, both maxillofacial and nonmaxillofacial.

Treatment of the mandibular fracture will vary from centre to centre, depending on the surgeons and availability of facilities. In our study, $69.4 \%$ of patients underwent open reduction and internal fixation, $15.8 \%$ were treated with intermaxillary fixation and $11.7 \%$ were treated conservatively. Decision of treatment was mainly depended on the favourability of the fracture and functional assessment. However, outcome of the treatment was not included in this study.

The high incidence of MVA especially motorcycle-related accidents, suggests the need for greater awareness regarding road safety in our community. Strict re-enforcement of seatbelt and helmet legislations should be accomplished; especially in driver education programs. Motorcyclists should be educated about the availability and type of helmet, suitability of the helmet size (especially in paediatric age group) and the need to fasten the chinstraps to achieve adequate protection. These are the new proposed preventive measures to reduce traffic accidents: increasing the age limit for motorcycle license, emphasising parents' responsibility for underage and illegal motorcyclists, rigid requirement for license renewal and the use of airbags for cars.

For medical practitioners, this study has shown the correlation between the cause of injury and the site/number of mandibular fractures, as well as, concurrent maxillofacial and nonmaxillofacial injuries. This finding has emphasises on the importance of obtaining a detailed history of mechanism injury and proper examination to ensure accurate diagnosis and treatment.

Epidemiology study of mandibular fracture between areas or countries is important to reflect on the trend of incidences over time. It is crucial to provide the necessary information for concerned fields, development and evaluation effectiveness of preventive programs aimed at reducing the incidence of facial injury. As reported by Mouzakes et al. [27], the combined use of airbags and seatbelts have resulted in the reduction of facial injury incidences compared to the individual use of airbags or seatbelts alone.

\section{Conclusion}

In our study, mandibular fractures and concomitant maxillofacial injuries are mainly caused by MVA, with the highest incidence of motorcycle-related accidents involving 10 to 19 years age group. These incidences 
are preventable with effective education within the community and the enforcement of road safety laws. Continuous long-term data collection for maxillofacial injuries will help in evaluating the effectiveness of the preventive measures that been carried out over time.

\section{References}

[1] Chrcanovic BR, Abreu MH, Freire-Maia B, Souza LN, 1,454 mandibular fractures: a 3-year study in a hospital in Belo Horizonte, Brazil, J Craniomaxillofac Surg, 40(2), 2012, 116-123.

[2] Brasileiro BF, Passeri LA, Epidemiological analysis of maxillofacial fractures in Brazil: a 5-year prospective study, Oral Surg Oral Med Oral Pathol Oral Radiol Endod, 102(1), 2006, 28-34.

[3] Kyrgidis A, Koloutsos G, Kommata A, Lazarides N and Antoniades K, Incidence, aetiology, treatment outcome and complications of maxillofacial fractures. A retrospective study from Northern Greece, J Craniomaxillofac Surg, 41(7), 2013, 637-643.

[4] Tay Keng Kiong, Wan MAhadzir Wan Mustafa and Ganasalingam Sockalingam, Pediatric Facial Fractures: One-year Survey of 23 Government Hospitals in Malaysia Asian, J Oral Maxillofac Surg, 19(1), 2007, 30-33.

[5] Mohammad Hosein Ansari, Maxillofacial fractures in Hamedan province, Iran: a retrospective study (1987-2001), Journal of Cranio-Maxillofacial Surgery, 32(1), 2004, 28-34.

[6] Taiser Al-Khateeb and Farzad Mohammad Abdullah, Craniomaxillofacial injuries in the United Arab Emirates: a retrospective study, J Oral Maxillofac Surg, 65(6), 2007, 1094-1101.

[7] Nordin R, Rahman NA, Rashdi MF, Yusoff A, Rahman RA, Sulong S, Nur AM, Razak NA, Jabar MNA, Ibrahim MI, Mohamed N, Ahmad SHR and Ramli R, Oral and maxillofacial trauma caused by road traffic accident in two university hospitals in Malaysia: A cross-sectional study, Journal of Oral and Maxillofacial Surgery, Medicine, and Pathology, 27(2), $2014,166-171$.

[8] Ellis E, Moos KF and El-Attar A, Ten years of mandibular fractures: an analysis of 2,137 cases, Oral surgery, oral medicine, oral pathology, 59(2), 1985, 120-129.

[9] De Matos FP, Arnez MF, Sverzut CE and Trivellato AE, A retrospective study of mandibular fracture in a 40-month period, Int J Oral Maxillofac Surg, 39(1), 2010, 10-15.

[10] Hai-Won Jung, Baek-Soo Lee, Yong-Dee Kwon, Byung-Jun Choi, Jung-Woo Lee, Hyun-Woo Lee, Chang-Sig Moon and JooYoung Che, Retrospective clinical study of mandible fractures, J Korean Assoc Oral Maxillofac Surg, 40(1), 2014,21-26.

[11] Rashid A, Eyeson J, Haider D, Van Gijn D and Fan K, Incidence and patterns of mandibular fractures during a 5-year period in a London teaching hospital, Br J Oral Maxillofac Surg, 51(8), 2013, 794-798.

[12] Umar Kamali and Abdullah Pohchi, Mandibular fracture at HUSM: a 5 year retrospective study, Achieves of Orofacial Sciences, 4(2), 2009, 33-35

[13] Subhashraj K, Ramkumar S and Ravindran C, Pattern of mandibular fractures in Chennai, India, Br J Oral Maxillofac Surg, 46(2), 2008, 126-127.

[14] M. Adi, G.R. Ogden and D. M. Chisholm, An analysis of mandibular fracture in Dundee, Scotland (1977-1985), Br J Oral Maxillofac Surg, 28(3), 1990, 194-199.

[15] B. P. Allan and C.G. Daly, Fracture of mandible: A 35-year retrospective study, Int J Oral Maxillofac Surg, 19(5), 1990, 268271.

[16] Kirk L. Fridrich, Gustavo Pena-Velasco and Robert A.J Olson, Changing Trends with Mandibular Fractures: A review of 1,067 cases, J Oral Maxillofac Surg, 50(6),1992,586-589.

[17] P Dongas and GM Hall, Mandibular fracture patterns in Tasmania, Australia, Australian Dental Journal, 47(2), 2002, $131-137$.

[18] Rahul Sharma, Vijay L GRover and S Chaturvedi, Health-risk behaviors related to road safety among adolescent students, Indian Journal of Medical Science, 61(12), 2008, 656-662.

[19] Li-PingWong, Socio-demographic and behavioural characteristics of illegal motorcycle street racers in Malaysia, BMC Public Health, 11, 2011, 446.

[20] Sakr K, Farag IA and Zeitoun IM, Review of 509 mandibular fractures treated at the University Hospital, Alexandria, Egypt, Br J Oral Maxillofac Surg, 44(2), 2006, 107-111.

[21] Wimon Sirimaharaj and Kasemsak Pyungtanasup, The epidemiology of mandibular fracture treated at Chiang Mai University Hsopital: a review of 198 cases, J Med Assoc Thai, 91(6), 2008, 868-874.

[22] Bormann KH, Wild S, Gellrich NC, Kokemuller H, Stuhmer C, Schmelzeisen R and Schon R, Five-year retrospective study of mandibular fractures in Freiburg, Germany: incidence, etiology, treatment, and complications, J Oral Maxillofac Surg, 67(6), 2009, 1251-1255.

[23] Shiva Bharani KSN, Rajay A.D. Kamath, Shubha Lakshmi S, V. Deepti and Suhas Prabhakar, Mandibular trauma in Central Karnataka, India - An outcome of 483 cases at a regional maxillofacial surgical unit, J Oral Maxillofac Surg, Med and Path, 27(3), 2015, 308-317.

[24] Col GK Thapliyal, Col R Sinha, Col PS Menon and Surg Lt Cdr A Chakranarayan, Management of mandibular fractures. Medical J Armed Forces India, 64(3), 2007, 218-220.

[25] Mittal G and Mittal S, Mandibular fractures at veer chandra singh garhwali government medical science and research institute, garhwal region, uttarakhand, India: a retrospective study, Ann Med Health Sci Res, 3(2), 2013, 161-165.

[26] Abdullah WA, Al-Mutairi K, Al-Ali Y, Al-Soghier A and Al-Shnwani A, Patterns and etiology of maxillofacial fractures in Riyadh City, Saudi Arabia, Saudi Dent J 25(1), 2013, 33-38.

[27] Mouzakes J, Koltai PJ, Kuhar S, Bernstein Dan S, Wing P and Salsberg E, The Impact of Airbags and Seat Belts on the Incidence and Severity of Maxillofacial Injuries in Automobile Accidents in New York State, Archives of Otolaryngology-Head \& Neck Surgery, 127(10), 2001, 1189. 